\title{
EDUCACIÓN RELIGIOSA EN ESCUELAS PÚBLICAS. A PROPÓSITO DE LA SENTENCIA CASTILLO DE LA CORTE SUPREMA DE ARGENTINA'
}

\section{Religious education in public schools. Comments on the sentence Castillo of the Supreme Court of Argentina}

\author{
GONZALO GABRIEL CARRANZA ${ }^{2}$ \\ Universidad Autónoma de Madrid \\ gonzalo.carranza@uam.es
}

Cómo citar/Citation

Gabriel Carranza, G. (2018).

Educación religiosa en escuelas públicas. A propósito de la sentencia Castillo de la Corte Suprema de Argentina. Anuario Iberoamericano de Justicia Constitucional, 22, 103-131. doi: https://doi.org/10.18042/cepc/aijc.22.04

\section{Resumen}

La enseñanza de contenido religioso en las escuelas públicas de la provincia de Salta, República Argentina, propició un amparo colectivo que llegó a ser resuelto por la Corte Suprema de Justicia de aquel país austral. El propósito de este comentario es

1 Este trabajo se enmarca en el proyecto de investigación del Ministerio de Economía y Competitividad de España (DER2016-78391-P) sobre «El control de la ley: constitucional, comunitario y convencional», cuyos investigadores principales son César Aguado Renedo y Antonio López Castillo, y en el proyecto de investigación de la Universidad Blas Pascal de Argentina (159-20180224-97) sobre «Desafíos constitucionales derivados de la jurisprudencia dictada durante el año 2017 por la Corte Suprema de Justicia de la Nación de Argentina».

2 Abogado, doctorando en Derecho, Gobierno y Políticas Públicas y docente e investigador del Área de Derecho Constitucional de la Universidad Autónoma de Madrid. 
recorrer el camino procesal que siguió la causa hasta llegar a la cúspide del sistema y analizar el contenido de los argumentos vertidos por la Corte para resolverlo.

En la sentencia, no solo se hace alusión a la relación entre Estado e Iglesia, sino también al amplio margen de apreciación que poseen las provincias en Argentina, todo ello a la luz del control de constitucionalidad y convencionalidad. Así, se tratará de precisar cuáles son los derechos en juego y cómo se ha estructurado el razonamiento de la Corte.

\section{Palabras clave}

Enseñanza religiosa; Estado; Iglesia; control de constitucionalidad; control de convencionalidad.

\section{Abstract}

The teaching of religious content in public schools in the province of Salta, Argentina, led to a collective action that was resolved by the Supreme Court. The purpose of this comment is to go through the procedural path that followed the case until reaching the top of the system and analyze the content of the arguments made by the Court to resolve it.

In the ruling, the Court paid special attention to the relationship between State and Church, and it has analyzed the wide margin of appreciation that the provinces have in Argentina, all under the light of the control of constitutionality and conventionality. Thus, we will try to specify which rights are at stake and how the Court's reasoning has been structured.

\section{Keywords}

Religious teaching; State; Church; control of constitutionality; control of conventionality. 


\section{SUMARIO}

I. INTRODUCCIÓN. II. APROXIMACIÓN AL CASO: 1. Primera instancia. 2. Apelación ante la Corte de Justicia de Salta: 2.1. El voto de la mayoría. 2.2. El voto particular. 2.3. El dictamen del procurador general de la Nación. III. EL CASO ANTE LA CORTE SUPREMA DE JUSTICIA DE LA NACIÓN: 1. Una cuestión procesal que no es un sin más. 2. Una nación católica apostólica romana: el alcance del art. 2 de la Constitución Nacional. 3. El principio de neutralidad. 4. La reglamentación de la enseñanza religiosa en las escuelas públicas y la doctrina de la categoría sospechosa. 5. La valoración de la prueba y el contexto social. 6. Otros (importantes) derechos en juego. 7. La disidencia parcial: 7.1. La educación religiosa que no vulnera la Constitución 7.2. Libertad religiosa y educación: el diseño curricular como parámetro de constitucionalidad. 7.3. El fallo en disidencia. IV. CONCLUSIONES. BibLIOGRAFía.

\section{INTRODUCCIÓN}

En diciembre de 2017, la Corte Suprema de Justicia de la Nación Argentina (en adelante, y alternativamente, Corte o CSJN) dictó sentencia en una causa con grandes repercusiones, en la que se analizó particularmente si en las escuelas públicas de la provincia de Salta era posible impartir enseñanza religiosa.

El presente análisis pretende, a la luz de la sentencia, tomar en consideración las posturas de las diversas partes que actuaron en las distintas etapas procesales que la causa siguió hasta llegar al máximo tribunal de Argentina. Por ello, habrá que atender no solo a sus argumentos, sino también a las pruebas que han aportado para lograr la convicción de los jueces que tuvieron que decidir.

No se pretende, por lo tanto, centrar la atención solamente en la sentencia de la Corte, sino ver la causa en su conjunto. De esta manera, uno de los propósitos será comprender cuáles han sido los argumentos vertidos por los diversos tribunales que han entendido en el caso para llegar a su solución. Solo analizándolos conjuntamente será posible apreciar cómo existen ciertas miradas que atienden únicamente a la realidad local, mientras que hay otras que miran desde lo alto, aportando objetividad y neutralidad.

Se estructurará el comentario, entonces, a través de las etapas procesales que se han seguido hasta llegar a la cúspide del poder judicial en Argentina. 


\section{APROXIMACIÓN AL CASO}

El 12 de diciembre de 2017, la Corte Suprema de la Nación de la República Argentina, dictó sentencia en el marco de la causa Castillo, Carina Viviana y otros cl Provincia de Salta - Ministerio de Educación de la Prov. de Salta s/ amparo.

Antes de entrar de lleno en el análisis, cierto es que la causa somete a quien se aproxima a ella a la compleja relación entre Estado e Iglesia, uno de los debates más antiguos que existen, del cual la República Argentina no ha estado exenta.

La extensión territorial y la diferencia entre los pueblos que existe en un Estado tan amplio hacen que el fenómeno religioso sea más o menos fuerte según el lugar donde uno se encuentre. Hay espacios donde el fervor religioso es seguido por una mayoría significativa de personas, y otros donde el multiculturalismo ha dejado de lado las tradiciones de antaño.

Ahora bien, en Argentina ha existido desde los debates de la Revolución de mayo una gran injerencia de la Iglesia en los asuntos políticos y en los valores de la sociedad, y no se puede renegar de los antepasados al respecto. Esta situación ha sido similar en muchos Estados del mundo, y es una situación bien descrita por Calvo Espiga (2017: 13), quien ha precisado que «especialmente en el pasado, dado el carácter profundamente religioso de los pueblos, la religión infundía sus propios valores en las dimensiones organizativas fundamentales de sus respectivas sociedades, llegando incluso, en algunos casos, a asumir el gobierno directo y el control político de las mismas, además del espiritual».

No es fácil realizar un recorrido a través de los cauces procesales que discurrieron en torno al caso, por cuanto las partes que lo integran son numerosas y los estadios procesales, también. La causa llama la atención no solo porque la última decisión la tuvo la CSJN, sino porque esta, para resolver, echó mano de diferentes institutos procesales poco usados en el Alto Tribunal, como lo es el amicus curiae.

Tal cual lo relata la Corte, la causa se inició porque un grupo de madres de alumnos de escuelas públicas de la provincia de Salta (una provincia al noroeste de Argentina, a poco más de $1200 \mathrm{~km}$ de la ciudad autónoma de Buenos Aires), junto con la Asociación por los Derechos Civiles (ADC) ${ }^{3}$,

3 Según se puede consultar en la propia página web de la Asociación (www.adc.org.ar, consultada el 10-07-2018), «ADC es una organización no gubernamental, apartidaria y sin fines de lucro, cuyo objetivo es contribuir a afianzar una cultura jurídica e insti- 
consideró que ciertas prescripciones de la Constitución provincial y de la ley provincial de educación 7546 eran inconstitucionales.

Para lograr su cometido, la parte demandante inició una acción de amparo colectiva en contra del Ministerio de Educación del Gobierno provincial. La cuestión no es un sin más, por cuanto este tipo de acción implica la representación de un colectivo de ciudadanos que se ven (o verían) afectados por la situación de hecho que, según plantean, acarrearía una vulneración de sus derechos fundamentales. Normalmente, este proceso ha sido utilizado con fines ambientales (Pinacchio, 2017), más que para la protección de otros derechos, pero por la incidencia de los efectos de la causa ha sido admitido desde primera instancia.

Particularmente, las actoras solicitaron que se declare la inconstitucionalidad del art. 27, inciso ñ de la ley provincial de educación, que establece que la instrucción religiosa «integra los planes de estudio y se imparte dentro de los horarios de clase, atendiendo a la creencia de los padres y tutores quienes deciden sobre la participación de sus hijos o pupilos. Los contenidos y la habilitación docente requerirán el aval de la respectiva autoridad religiosa».

Además, solicitaban la declaración de inconstitucionalidad del art. 8, inciso m de la referida ley y del art. 49 de la Constitución de la provincia de Salta, que disponen en idéntico sentido que «los padres y en su caso los tutores, tienen derecho a que sus hijos o pupilos reciban en la escuela pública la educación religiosa que esté de acuerdo con sus propias convicciones».

La pretensión de las accionantes se dirigía, también, a solicitar la inconstitucionalidad de las actividades de los funcionarios escolares de la provincia de Salta, quienes al aplicar la norma imponen, de hecho, una enseñanza obligatoria de la religión católica en las escuelas públicas provinciales, según aducen.

Lo descrito precedentemente buscaba, de igual manera, el cese de la enseñanza religiosa en las escuelas públicas y de toda práctica religiosa dentro del horario escolar, ya que consideraban que estas situaciones vulneraban ciertos derechos constitucional y convencionalmente reconocidos en Argentina ${ }^{4}$, como la libertad de culto, religión y conciencia, de igualdad, educación libre

tucional que garantice los derechos fundamentales de las personas, sustentada en los valores democráticos de nuestra Constitución Nacional».

4 Cabe recordar que, en la reforma constitucional del año 1994, Argentina incorporó al bloque de constitucionalidad numerosos instrumentos internacionales de derechos humanos a los que les otorgó la misma jerarquía que la Constitución, conforme se puede apreciar en el art. 75 inciso 22 de la Carta Magna. Sobre los alcances y el contenido de este artículo, véase el comentario de María Angélica Gelli (2011: 217). 
de discriminación y respeto de las minorías étnicas y religiosas, y de privacidad.

\section{PRIMERA INSTANCIA}

El íter procesal llevado a cabo por las accionantes para llegar a la Corte Suprema no fue sencillo ni rápido, de ello dan cuenta las fechas de las sentencias y el amplio debate que se suscitó en torno al tema tanto en la sociedad civil como en el Congreso Nacional, donde se desarrolló una agenda que abrió el debate en una serie de temas que tocan de lleno las relaciones entre el Estado y la Iglesia católica.

Claro está, antes de llegar a la Corte Suprema (gracias a un recurso extraordinario federal), y en virtud de la estructura federal del sistema judicial, la causa se inició en Salta, ascendiendo en apelación hasta la Corte de Justicia de la propia provincia.

La causa tuvo inicio en la Cámara de Apelaciones en lo Civil y Comercial de la provincia de Salta, sala III, donde el vocal Marcelo Domínguez tuvo el primer contacto de la justicia con los hechos, como juez de amparo. Cabe destacar que, en el caso argentino, cada provincia tiene su propio sistema procesal y que en Salta el art. 87 de su Constitución prescribe que «todo Juez Letrado es competente para entender en la acción, aún en el caso que integrare un tribunal colegiado». Así, un juez de cámara (esto es, un tribunal colegiado) puede actuar unipersonalmente como juez de primera instancia en el amparo.

En aquella oportunidad, como se desprende de la sentencia, el juez relata que las accionantes aducen su legitimación activa como actores colectivos, ya que consideran que «los potenciales afectados no son solo los que se encuentran dentro de las estructuras escolares actualmente, sino también los que eventualmente ingresaran, dado el carácter obligatorio de la educación ${ }^{5} »$.

Según el juez, el acto se subsume dentro del supuesto del amparo, ya que «no se han arbitrado los medios necesarios tendientes a la contención escolar de niños y niñas no católicos» y que en la Constitución «se garantiza [...] la pluralidad religiosa, pero la falta de políticas de estado tornan a la ley inconstitucional en su ejecución y aplicación práctica ${ }^{6} »$.

Para llegar a su conclusión aporta ejemplos de diversas escuelas de distintos puntos de la provincia donde, al parecer, de producen hechos que «representan una amenaza a los conceptos de pluralidad y tolerancia religiosas, retroceso en términos prácticos, al otorgar a un credo en particular un espacio

\footnotetext{
5 Punto I de los considerandos de la sentencia de Cámara.

6 Ídem.
} 
que podría dedicarse a impartir elementos comunes a todos los niños y niñas de diversos cultos o bien sin ninguno ${ }^{7}$.

Relata que las accionantes consideran que se utiliza a la educación obligatoria como un dispositivo de reproducción de la religión hegemónica, y que las prácticas desarrolladas hasta el momento supondrían un acercamiento a una adopción de un credo estatal.

En la primera instancia participaron, además, el Ministerio de Educación provincial, el propio Estado provincial y el Ministerio Fiscal, que solicitaron el rechazo de los planteos de inconstitucionalidad. El último de los participantes mencionado indicó, además, que considera que «existe un proceder omisivo lesivo de derechos de raigambre constitucional respecto de los niños que no profesan la religión católica ${ }^{8}$ ».

Por su parte, el asesor de incapaces, en su participación, destacó «que existe por parte del estado provincial una falta en cuanto a no contar con una opción para aquellas personas que no quieran concurrir a clases de religión, donde se les pueden enseñar valores o conceptos éticos, como así también darse la oportunidad a las otras religiones reconocidas en la Argentina para que puedan formular los programas acordes a su lineamiento doctrinario"».

El análisis normativo realizado por el juez no solo centra su atención en las disposiciones cuya inconstitucionalidad se aduce, sino que agrega a ello la disposición 45/09 de la Dirección General de Enseñanza Primaria y Educación Inicial de la provincia de Salta, que aprobó el contenido de los formularios en los que se pide a los padres o tutores de los alumnos que concreten la opción sobre la participación o no de sus hijos o pupilos en las clases de Religión, y la creencia en la que desearen fueran instruidos, indicando en este último caso la religión.

Según el vocal, es esta disposición «la que impone una práctica que no se condice con la efectiva vigencia de los derechos que se invocan lesionados, al poner en los hechos en evidencia a quienes no profesan la religión mayoritaria, quienes deben expresar a qué culto o credo pertenecen para ser separados del resto y dispuestos para realizar otras actividades, con relación a las cuales ha quedado demostrado que la desaprensión del Estado se evidencia patente y clara $^{10}{ }^{\prime}$.

Del razonamiento del magistrado se desprende que, según su parecer, no son inconstitucionales las disposiciones en su contenido, sino la forma en que

\footnotetext{
7 Ídem.

8 Punto IV de los considerandos de la sentencia de Cámara.

9 Punto V de los considerandos de la sentencia de Cámara.

10 Punto IX de los considerandos de la sentencia de Cámara.
} 
se ha procedido a ejecutarlas, dando lugar a un tratamiento que, en la práctica, a través de una diferenciación aparentemente neutra, pone a ciertos menores en una situación que culmina siendo discriminatoria, al ser "distintos» a sus pares que sí profesan la religión mayoritariamente practicada en la provincia.

Cabe destacar que el juez de Cámara trae a colación el marco convencional desde el cual hay que analizar la causa, prestando atención especialmente al art. 13, apdo. 3 del Pacto Internacional de Derechos Económicos, Sociales y Culturales, que establece:

Los Estados Partes en el presente Pacto se comprometen a respetar la libertad de los padres y, en su caso, de los tutores legales, de escoger para sus hijos o pupilos escuelas distintas de las creadas por las autoridades públicas, siempre que aquéllas satisfagan las normas mínimas que el Estado prescriba o apruebe en materia de enseñanza, y de hacer que sus hijos o pupilos reciban la educación religiosa o moral que esté de acuerdo con sus propias convicciones.

A raíz de este artículo, el Comité de Derechos Económicos, Sociales y Culturales en la observación general n. ${ }^{\circ} 13$, numeral 28 , dijo, en cuanto a los párrs. 3 y 4 del artículo mencionado, que «el párrafo 3 del artículo 13 contiene dos elementos, uno de los cuales es que los Estados Partes se comprometen a respetar la libertad de los padres y tutores legales para que sus hijos o pupilos reciban una educación religiosa o moral conforme a sus propias convicciones».

En relación con ello, tal como lo destaca el propio juez, el Comité considera que, en su opinión,

[...] este elemento del párrafo 3 del artículo 13 permite la enseñanza de temas como la historia general de las religiones y la ética en las escuelas públicas, siempre que se impartan de forma imparcial y objetiva, que respete la libertad de opinión, de conciencia y de expresión. Observa que la enseñanza pública que incluya instrucción en una determinada religión o creencia no se atiene al párrafo 3 del artículo 13, salvo que se estipulen exenciones no discriminatorias o alternativas que se adapten a los deseos de los padres y tutores.

Por otra parte, el Comité de Derechos Humanos, mediante la observación general n. ${ }^{\circ} 12$ interpreta el apdo. 2 del art. 18 del Pacto Internacional de Derechos Civiles y Políticos, que literalmente indica: «Nadie será objeto de medidas coercitivas que puedan menoscabar su libertad de tener o de adoptar la religión o las creencias de su elección». Dicha interpretación se resume en que no se puede obligar a nadie a revelar sus pensamientos o su adhesión a una religión o a unas creencias.

Asimismo, el apdo. 4 del art. 18 del mismo instrumento, que indica: «Los Estados Partes en el presente Pacto se comprometen a respetar la libertad 
de los padres y, en su caso, de los tutores legales, para garantizar que los hijos reciban la educación religiosa y moral que esté de acuerdo con sus propias convicciones», permite que en la escuela pública se imparta enseñanza de materias como la Historia General de las Religiones y la Ética, siempre que ello se haga de manera neutral y objetiva, lo que es incompatible con el adoctrinamiento de una religión o unas creencias particulares.

El fallo del vocal es sencillo: a su parecer, no hay ninguna inconstitucionalidad de las normas y obliga al Ministerio de Educación a adoptar las medidas necesarias para que cesen las conductas que se desarrollan en las instituciones públicas de educación primaria que imponen prácticas de la religión católica. Junto con ello, solicita adecuar el dictado de la materia Educación Religiosa a los parámetros de las observaciones del Comité de Derechos Humanos y del Comité de Derechos Económicos, Sociales y Culturales.

\section{APELACIÓN ANTE LA CORTE DE JUSTICIA DE SALTA}

Las peticionarias del amparo colectivo apelaron la decisión del vocal Domínguez ante la Corte de Justicia de Salta, máxima autoridad del Poder Judicial provincial. La sentencia del caso se dictó el 12 de julio de 2013, y puede analizarse siguiendo el voto de la mayoría (integrada por el presidente de la corte provincial, Guillermo A. Posadas, y los jueces de corte Guillermo Alberto Catalano, Gustavo Adolfo Ferraris y Sergio Fabián Vittar) y el voto particular del magistrado Abel Cornejo.

\subsection{El voto de la mayoría}

El voto de mayoría recuerda que el juez a quo declaró constitucionales las normas sujetas a examen y centró su análisis en argumentos sustentados en cuestiones fácticas y en su interpretación sustancial del caso.

Destacan que la Constitución Nacional no es indiferente a lo religioso ni agnóstica, pues no suspende el juicio acerca de la existencia de Dios, sino totalmente lo contrario. De ello, por ejemplo, se da cuenta tanto en el preámbulo como en el articulado del texto, aunque no mencionan específicamente a qué artículos refieren. Respecto a ello, consideran que «no implica menoscabo para posición religiosa o filosófica alguna desde que los arts. 14 y 19 reconocen la libertad de culto y la libertad de conciencia, respectivamente ${ }^{11}$ ».

Ante este escenario, creen que, si bien existe libertad religiosa, también existe la objeción de conciencia en todos los campos donde su disponibilidad

11 Considerando 2. ${ }^{\circ}$ de la sentencia de la Corte de Justicia de Salta. 
por el sujeto no arriesga ni perjudica los intereses de terceros, por lo que no advierten en qué medida los derechos invocados por los amparistas se encuentran vulnerados por las normas que regulan la educación religiosa en las escuelas.

Su interpretación de la libertad religiosa no se ciñe a un entendimiento de la exclusión de todo lo religioso, sino en la posibilidad de optar, sin presiones de ningún tipo, por un determinado camino de plenitud del ser; de allí que no se pueda imponer a todos los alumnos una visión atea o agnóstica del mundo. El argumento que utilizan ata a la libertad religiosa a la libertad de opción.

La Corte de Salta utiliza un argumento que condensa lo fáctico con lo normativo, al entender que el Estado está estructurado desde su fundación como una nación católica apostólica romana y que dicha provincia norteña tiene una población "mayoritariamente católica», lo que "se verifica en sus múltiples manifestaciones culturales y en las exteriorizaciones de su fe, como por ejemplo, la procesión en honor al Señor y la Virgen del Milagro que se realiza todos los años el día 15 de septiembre», donde se constata «la cada vez más numerosa cantidad de habitantes de los diferentes pueblos de la Provincia que peregrinan hacia la Capital y cuyos hijos se verían privados, por la oposición de un grupo, de ser instruidos en la fe de sus mayores ${ }^{12}$ ».

Los magistrados, a diferencia del juez que analizó el caso por primera vez, consideran que la decisión de requerir a los padres o tutores que manifiesten si desean que sus hijos permanezcan o no en la clase de religión no evidencia la utilización de un método que afecta a la igualdad de los niños, y tampoco es un hecho que implique discriminación alguna. A su parecer, la separación de los estudiantes, entre quienes reciben la enseñanza religiosa y quienes no lo hacen, «resulta razonable y no menoscaba el derecho a la igualdad ${ }^{13}{ }$. Esta razonabilidad deriva de la lícita decisión del legislador de brindar educación religiosa en las escuelas públicas.

Por su parte, la Corte de Justicia salteña consideró que la decisión tomada por el a quo, respecto de la orden de adecuación de las materias de enseñanza religiosa a las observaciones de los Comités reseñados era innecesaria, ya que de ninguna manera el orden jurídico provincial vulnera ni la Constitución Nacional ni los tratados internacionales de derechos humanos que son aplicables al caso.

Ahora bien, en relación con las cuestiones probatorias, el tribunal sí que considera probado que en algunos establecimientos escolares no se respeta

12 Considerando $3 .^{\circ}$ de la sentencia de la Corte de Justicia de Salta.

13 Considerando $5 .^{\circ}$ de la sentencia de la Corte de Justicia de Salta. 
a los alumnos que no profesan la religión católica o que, directamente, no profesan religión alguna. Consideran que no se han diseñado actividades curriculares alternativas a sus necesidades y, además, las prácticas religiosas exceden a las horas destinadas a su enseñanza. Más allá de eso, creen que quien debe arbitrar los medios para resolver estas cuestiones no es la propia Corte de Justicia, sino el juez de primera instancia, por contar con las vías procesales necesarias para ejecutar su propia decisión.

En definitiva, la decisión final del voto mayoritario fue la de rechazar la apelación y estimarla solo parcialmente, en cuanto que revocan la decisión de prohibir las prácticas religiosas en las escuelas, las que deberán efectuarse durante el horario fijado para la enseñanza de la materia, y disponen que se debe arbitrar un programa alternativo para quienes deseen ser instruidos en la religión católica.

\subsection{El voto particular}

Por otro lado, el voto particular del magistrado Abel Cornejo, si bien concuerda en la estimación parcial, considera que el rechazo de la apelación no se debe a los mismos motivos que aducen sus compañeros, sino a que la Corte de Justicia no debe analizar el caso, por cuanto «de ningún modo un poder constituido puede declarar inconstitucional una norma o cláusula de la Constitución Provincial, so pretexto de interpretación, en virtud de que la ley fundamental de la Provincia sólo puede ser modificada o alterada por una Convención Constituyente convocada a tal efecto ${ }^{14}$ ».

El voto de este magistrado, como se aprecia, tiende a llevar el debate hacia la relación entre poder constituyente y poder constituido, centrando su atención solo en el pedido de inconstitucionalidad de la propia Constitución provincial, pero dejando de lado las normas infraconstitucionales que se habían puesto en duda y, además, la ejecución práctica de la ley.

\subsection{El dictamen del procurador general de la Nación}

La decisión de la Corte de Justicia de Salta no fue de recibo por parte de las actoras, quienes insistieron en una revisión de la decisión. Para ello, interpusieron el recurso extraordinario federal y llegaron a la Corte de Justicia de la Nación, previa concesión por el a quo el 1 de septiembre de 2014.

Llegada la causa a la Corte, comenzaría un largo proceso que llevaría tres años de una actividad de escucha y análisis por parte de sus miembros,

14 Considerando $10^{\circ}$ del voto particular de la sentencia de la Corte de Justicia de Salta. 
en medio de la modificación de la integración del Alto Tribunal, al que llegarían dos nuevos ministros, uno de los cuales ha tenido un papel esencial en la deliberación de la sentencia y en la argumentación del voto particular por disidencia parcial de la decisión.

Antes de afrontar el estudio de lo decidido por la Corte, es primordial analizar el dictamen del procurador general de la Nación, Victor Abramovich, de 10 de marzo de 2017.

Del dictamen es posible advertir, en primer término, un relato de los hechos acaecidos en la instancia inmediatamente anterior, donde el procurador destaca que la Corte de Justicia analizó el caso desde una óptica fáctica subjetiva, asumiendo que la provincia de Salta tiene una población mayoritariamente católica y que la falta de enseñanza católica en las escuelas públicas generaría un perjuicio a los niños que carecen de recursos para poder concurrir a una escuela privada donde, claro está, el tribunal presume que se enseña religión católica a todos por igual, dejando de lado otro dato de color, cual es que no todas las escuelas privadas son adscritas al culto católico.

Además, recalcó que uno de los motivos que llevó a la Corte de Justicia a considerar que no había afección al derecho de igualdad era que la separación de los niños constituía una medida razonable y un medio adecuado a fin de brindar educación de acuerdo con la convicción de los padres.

El procurador, luego de señalar que el recurso fue correctamente concedido, centra su atención en las pruebas de la causa, por cuanto lo que quiere dilucidar es si realmente han sido las prácticas las que han lesionado los derechos constitucionales de las personas representadas colectivamente por las accionantes.

Para llegar al punto clave, no deja de atender una cuestión esencial de fondo: la autonomía provincial condensada en el artículo 5. ${ }^{\circ}$ de la Constitución Nacional consagra el valor de la diversidad que conlleva el régimen federal de Gobierno argentino. Por ello, si bien se requiere que en lo esencial exista una coincidencia entre las constituciones provinciales y la de la Nación, cierto es que este artículo no exige que sean idénticas, ni mucho menos una copia literal o mecánica. Se ha dicho, respecto a este artículo, que «las provincias dictan sus constituciones que ya no están sujetas a la revisión política por parte del Congreso Federal, pero sí al control de constitucionalidad de la Corte Suprema y a la eventual intervención federal para restablecer la forma republicana de gobierno» (Gelli, 2011: 55).

$\mathrm{El}$ argumento del procurador es el siguiente: «El solo hecho de que la constitución salteña reconozca, en ejercicio de su potestad constituyente, derechos que no están previstos en la nacional no conlleva su invalidez, siempre 
que ello respete los derechos y garantías previstos por el régimen federal ${ }^{15}$ ». Ahora bien, hay que ver si tanto en su contenido normativo como en su faz práctica esta cuestión afecta o no los derechos constitucionales ( $\mathrm{y}$, hay que agregar, convencionales) reconocidos por el Estado.

El análisis de la prueba, así, resulta trascendente. El procurador general considera que ha sido suficientemente probado que en las escuelas públicas solo se han impartido clases del culto católico, lo que se desprende de libros y cuadernos de los alumnos, de las manifestaciones de los propios padres, del informe de visitas de la supervisora religiosa, de coberturas periodísticas del caso, de la formación que reciben los maestros y de la intervención del arzobispo de Salta en el proceso de acceso a plazas docentes.

Se ha probado, afirma el procurador, que alumnos que son ateos, evangelistas, testigos de Jehová, mormones y adventistas han recibido educación católica en las escuelas públicas. De la misma manera, es consciente que muchos padres habían indicado expresamente que no profesaban una religión o que lo hacían respecto a una específica distinta al catolicismo, pero consentían que sus hijos recibiesen clases de religión para que estos no fuesen individualizados y segregados, o simplemente por cuestiones de seguridad, para que estuviesen contenidos en un aula durante esas horas.

De la causa se desprende que «en ningún caso se acreditó la existencia de una educación alternativa en otras religiones o en otras materias que estuviera disponible para los que no deseaban recibir instrucción en la religión católica ${ }^{16}{ }_{\text {». }}$.

Lo que importa, según el procurador, además de la forma práctica en que se llevó a cabo la implementación de la ley, ha sido el canal burocrático elegido para hacerlo, a través de un formulario que ha obligado a quienes desean recibir instrucción religiosa a revelar su religión o creencias, y a poner en evidencia a aquellos que no quieren hacerlo, quienes llegaron a recibir la condición de «no creyentes» en el expediente académico personal.

Por todo lo apuntado, la instrucción de la religión católica en el horario escolar y como parte del plan de estudios ha resultado, en la práctica - según el procurador-, una grave interferencia en distintas dimensiones de la libertad de religión y conciencia, derivada no solo del articulado de la propia Constitución, sino de numerosos tratados internacionales de derechos humanos, con jerarquía constitucional. Así, los actos prácticos son a los que el procurador les otorga la calidad de inconstitucionales e inconvencionales.

El procurador da tres argumentos para llegar a su conclusión. En primer lugar, ha existido una coacción directa e indirecta en la elección de niños,

15 Considerando IV del dictamen del procurador general de la Nación.

16 Considerando V del dictamen del procurador general de la Nación. 
niñas, padres y representantes legales sobre sus creencias, cuestión estrictamente prohibida por el art. 14 de la Constitución y por los instrumentos internacionales. Esto ha generado una indebida presión en la libertad de elección, lo que asume dimensiones mayores si se tiene en cuenta que esta situación se ha dado en el marco de la escuela primaria, donde los niños tienen especial vulnerabilidad.

En segundo lugar, considera que la organización religiosa dentro del horario escolar y como parte del plan de estudios ha importado un impacto desigualitario y discriminatorio de los niños, sujetos a una especial protección. El hecho de ser señalados como "no creyentes» puede significar un elemento de coacción, estigmatización y discriminación irrazonables.

Por último, el hecho de que los alumnos no católicos sean instruidos en el catolicismo durante el horario escolar implica una clara vulneración a su libertad y la de sus padres y representantes legales a recibir una educación religiosa o moral que esté de acuerdo con las convicciones que poseen, lo que también está protegido por la propia Constitución y los tratados a ella incorporados.

Ataca a la Corte de Justicia de Salta en relación con su argumento mayoritario, entendiendo que por más que haya una religión que sea profesada por un significativo grupo de personas en su territorio, ello no es justificativo suficiente para que se vulneren derechos de las minorías.

El procurador, además de argumentar y aportar a la CSJN una visión del caso, se preocupa por encontrar una solución que permita conciliar lo sustantivo con lo material, proponiendo un sistema alternativo de enseñanza de esta materia que atienda a la diversidad de realidades que existen, lo que seguramente tendrá mayores costos para la familia y para el Ministerio de Educación, pero que, en la balanza de sacrificios, considera compensado por la ventaja de no vulnerar derechos fundamentales.

Por fin, su dictamen concluye con la declaración de constitucionalidad de la Constitución provincial y de la ley de educación de la provincia, salvo por el inciso ñ del art. 27, que prevé que la enseñanza religiosa deberá dictarse dentro del horario de clase. De la misma manera, considera que es inconstitucional la disposición 45/09 de la Dirección General de Educación Primaria e Inicial de Salta, por lo que finalmente agrega que debe ordenarse el cese de la enseñanza religiosa dentro del horario escolar y como parte de los planes de estudio en las escuelas públicas.

Respecto al dictamen, no han faltado críticas, como la realizada por Sofía Calderone (2017), quien ha considerado que no existe en sí una cuestión federal que habilite y justifique la intervención de la Corte Suprema y, apoyando la decisión de la Corte de Salta, considera que la educación religiosa forma parte de una educación integral, por lo que su confinamiento del horario escolar solo recabaría el derecho de aquellos que sí desean recibir dicha 
formación, lo que redundaría en un desprecio de una tradición seguida desde antaño por la provincia de Salta.

\section{EL CASO ANTE LA CORTE SUPREMA DE JUSTICIA DE LA NACIÓN}

La causa fue resuelta por la CSJN el 12 de diciembre de 2017, en el marco de un año en el que este tribunal resolvió numerosos procesos que refieren a cuestiones constitucionales ${ }^{17}$, lo que ha dado cuenta de un cambio de óptica del Alto Tribunal en relación con cuestiones esenciales del ordenamiento jurídico argentino. Quizá, este cambio se ha debido a la renovación de su integración, sobre todo con la incorporación de juristas de reconocido prestigio ligados al mundo del derecho constitucional.

Un dato a destacar ha sido que el magistrado Carlos Rosenkrantz (uno de los dos últimos en incorporarse a la CJSN) se excusó de participar en la causa, por haber participado en la Asociación por los Derechos Civiles (ADC), una de las actoras del amparo colectivo, al momento de comenzar el proceso.

La sentencia se dictó con una mayoría de tres ministros (Ricardo Luis Lorenzetti, Elena I. Highton de Nolasco y Juan Carlos Maqueda) y con un voto que expresaba una disidencia parcial del ministro Horacio Rosatti.

El análisis sustantivo de la sentencia, por su extensión, se realizará a través de diversos puntos que tratan de condensar la doctrina de la Corte al respecto.

\section{UNA CUESTIÓN PROCESAL QUE NO ES UN SIN MÁS}

Antes de realizar la inmersión en el contenido de la sentencia, no es un dato menor el hecho de que la Corte haya celebrado diversas audiencias públicas que han tenido como fin recabar argumentos y escuchar a la sociedad civil, antes de dictar su fallo.

Las audiencias públicas informativas fueron realizadas de conformidad a la Acordada 30/2007 de la Corte. Estas se llevaron a cabo los días 16, 17, 30 y 31 de agosto de 2017. Durante las tres primeras jornadas expusieron los amigos del tribunal (amicus curiae) que habían sido admitidos conforme a la Acordada 7/2013 de la misma Corte y en la última lo hicieron los

17 Entre otros, las causas Ministerio de Asuntos Exteriores, Muiña o Schiffrin, en las que el tribunal refirió a temas centrales como los límites del control de convencionalidad, la cuestión del cómputo de las penas de prisión de los genocidas de la última dictadura militar o la constitucionalidad de la propia Constitución Nacional luego de la reforma de 1994. Para profundizar, véase Carranza, 2017. 
representantes de las partes, quienes fueron interrogados en relación con diversos aspectos de la controversia. Finalmente, tomaron la palabra los oradores designados como terceros voluntarios admitidos al proceso.

Tal cual se puede consultar en la página web de la $\mathrm{CSJN}^{18}$, los amicus curiae ascendían a un total de 35, entre los que se encontraban partidos políticos, asociaciones civiles, centros académicos, juristas, educadores, y personas de la sociedad civil ${ }^{19}$. Esta institución ha sido receptada desde hace poco tiempo, y ha sido considerada como un instituto que favorece la democracia deliberativa en el seno del tribunal (Mena Vázquez, 2010).

Ha de considerarse un acierto que la Corte utilice este instrumento en un caso controvertido como el que debió resolver, lo que concuerda con la presunción de la que partía Víctor Bazán (2006: 44) cuando afirmaba que el amicus curiae "puede entrañar un instrumento válido para funcionar en la resolución de cuestiones controversiales y que presenten significativos dilemas éticos o de otra índole, por ejemplo, de análisis constitucional de una normativa de importancia o sensibilidad públicas, en la que la decisión por recaer sea susceptible de marcar una guía jurisprudencial para otros casos pendientes».

Este recurso ha sido trascendente para la causa, ya que la sentencia de la Corte se esperaba para resolver este conflicto que afectaba a un sector de la sociedad salteña y, puede decirse, de otras provincias también. Así, hay que destacar la conveniencia de abrir las puertas del tribunal a la sociedad para poder aportar argumentos y posiciones en relación con el caso en abstracto y en particular.

\section{UNA NACIÓN CATÓLICA APOSTÓLICA ROMANA: EL ALCANCE DEL ART. 2 DE LA CONSTITUCIÓN NACIONAL}

La primera cuestión que trata de dilucidar la Corte Suprema es si es válida la afirmación que realiza la Corte de Salta, cuando afirma que «la Argentina está jurídicamente estructurada desde su fundación como una nación católica apostólica romana». Esta es una cuestión de trascendencia para la causa, por cuanto es el basamento sobre el que se asienta la argumentación de la sentencia que la CSJN tiene que controlar.

18 Disponible en: http://bit.ly/2PQCE1V (fecha de consulta: 11-07-2018).

19 Algunos de los textos que dieron lugar a las exposiciones se pueden consultar en internet. Por ejemplo, el del Centro de Estudios sobre Derecho y Religión de la Universidad Adventista de La Plata (disponible en http://bit.ly/2B4AlzY, fecha de consulta: 11-07-2018) o el del Centro de Estudios Legales y Sociales —CELS— (disponible en: http://bit.ly/2B4rfn0, fecha de consulta: 11-07-2018). 
Para poder resolver esta cuestión, la Corte refiere a hechos históricos, ya que, en la Asamblea Constituyente de 1853, la cuestión emergió al debatirse el art. 2..$^{\circ}$ de la Constitución, el que, según ha quedado redactado (a modo de declaración), señala que «el gobierno federal sostiene el culto católico apostólico romano».

El segundo artículo de la Constitución no ha sido modificado a lo largo de la historia y se mantiene hoy en día tal cual fue redactado originariamente. Cabe destacar que, por ejemplo, en los debates de la reforma de 1860 (al reincorporarse Buenos Aires al Estado argentino) sí que quiso revisar su redacción bajo propuesta del convencional Frías, pero otros convencionales como Portela o Sarmiento (quien llegó a ser presidente de la Nación) solicitaron que fuese retirada.

Frente a la propuesta llevada a cabo para la redacción del artículo, la Corte recuerda que no hubo un consenso, por cuanto, por un lado, existieron posturas conservadoras que sí apoyaban la forma en que se había escrito (por ejemplo, los convencionales José Benjamín Gorostiaga, Manuel Pérez, Manuel Leiva o Pedro Zenteno). Aun esto, existían convencionales liberales como Lavaisse (quien, incluso, era sacerdote), que pensaba que la Constitución no debía intervenir en las conciencias, sino reglar solo el culto exterior. Esta última posición tenía una gran influencia del Anteproyecto de Alberdi, de la cual los conservadores se apartaron, como lo señala Diego Botana (2018: 11).

La redacción actual, sin lugar a dudas, no establece una religión oficial del Estado, a diferencia de las propuestas que se habían visto en las Constituciones provisorias de 1819 o 1826, que no llegaron a surtir efectos normativos. Por ello, se ha dicho que «la confesionalidad de nuestro estado cabe en la tipología de la secularidad» (Bidart Campos, 2013: 542).

El debate en torno a este artículo se centra en el verbo utilizado: «sostener», lo que implica el acto de «sostenimiento económico» del culto católico por parte del Estado. Esta situación no la convierte, claro está, en una religión única, ya que «ningún culto reviste el carácter de religión oficial del estado argentino $0^{20}$ », cuestión que ya había sido resuelta desde antaño, cuando se afirmó que «la aludida norma constitucional se limita a privilegiar a la Iglesia Católica en sus relaciones con el Estado coadyuvando, a la vez, al sostén y protección económica de los gastos de ese culto, los cuales serían pagados por el tesoro nacional, incluidos en el presupuesto y sometidos, por consiguiente, al poder del Congreso ${ }^{21}$ ».

Ahora bien, la academia no ha tenido la misma opinión que desde antaño mantiene la Corte. Como lo ha afirmado el mayor constitucionalista

20 Considerando $8 .^{\circ}$ de la sentencia de la CSJN.

21 Fallos 312: 122. 
contemporáneo de Argentina, el verbo que se utiliza en el artículo «quiere decir dos cosas [...]: a) la unión moral del estado con la Iglesia, y b) el reconocimiento de ésta como persona jurídica de derecho público» (Bidart Campos, 2013: 544). El mismo autor ha sostenido que «el art. $2^{\circ}$ tampoco tiene el alcance de establecer como obligación del gobierno federal la de subsidiar económicamente al culto católica», sino que esta constituye «una mera ayuda financiera» (Bidart Campos, 2013: 543).

\section{EL PRINCIPIO DE NEUTRALIDAD}

El hecho de que Argentina no sea un Estado con religión oficial implica una cierta neutralidad esperable en relación a la materia religiosa, lo que claramente quedó sobre la mesa cuando, en 1994, por ejemplo, la reforma constitucional más profunda de la Carta Magna eliminó la necesidad de ser católico para acceder al cargo de presidente de la Nación.

En aquella oportunidad, además, se cambió la redacción de la llamada "cláusula del progreso» (art. 75, inciso 19 de la Constitución) para que el adelanto esperable a través de la legislación federal se realice sin discriminación alguna, garantizando la igualdad de oportunidades y la promoción de los valores democráticos. Además, en relación con la educación pública (cuestión central en este asunto), declaró específicamente que debería perseguir los principios de gratuidad y equidad.

En el debate sobre la reforma del artículo, según reseña la Corte, sí que hubo disenso en cuanto a si debía indicarse expresamente que la educación pública debía ser laica o no. En aquellos días, si bien hubo posiciones que propendían a su incorporación (por ejemplo, se pueden apreciar los discursos de los convencionales Del Bono, Gómez de Marelli, Sánchez García o Puiggrós), finalmente no se llegó a incorporar específicamente dicha reserva. Ahora bien, la Corte reseña específicamente que «más allá de estas posiciones sobre el modo en que los convencionales entendían que debía formularse la norma, todos aludieron al carácter laico de la educación pública, como un principio clave para asegurar la promoción de los valores democráticos y la igualdad de oportunidades y posibilidades sin discriminación alguna ${ }^{22}$ ».

El contenido del principio de neutralidad que debe seguir el Estado según la Corte- comprende la posibilidad de profesar o no libremente el culto en el ámbito escolar. Para llegar a esta conclusión recurre a la misma reforma constitucional de 1994, y presta atención al contenido de los tratados internacionales de derechos humanos como el art. 13, apdo. 3 del Pacto

22 Considerando $13 .^{\circ}$ de la sentencia de la CSJN. 
Internacional de Derechos Económicos, Sociales y Culturales; el art. 12, apdo. 4 de la Convención Americana sobre Derechos Humanos, o el art 18, apdo. 4 del Pacto Internacional de Derechos Civiles y Políticos, todo ello con la interpretación legítima de los órganos competentes para hacerlo.

Esta neutralidad esperable del Estado es, según Gil Domínguez (2017: 2), muestra del paradigma secular con tendencia a la laicidad argentino o, como le da en llamar, «modelo aconfesional», lo que, según él, «se vincula con la actitud de equidistancia e imparcialidad que el Estado está obligado a sostener frente a los exponentes individualizados del fenómeno religioso que no constituyen un ejercicio del derecho fundamental y del derecho humano a la libertad de religión y de conciencia de las personas o de las comunidades».

El resultado de la argumentación a la que llega la Corte es que esta neutralidad estatal no solo importa la no preferencia de una posición religiosa en particular, sino también «una faz de tolerancia hacia todos aquellos que quieran profesar su culto en el ámbito escolar ${ }^{23}{ }$. Si se usa esta óptica para analizar el art. 49 de la Constitución de Salta, claro está que no habría una conculcación de derechos, por cuanto esta sigue casi en su literalidad lo dispuesto por los instrumentos internacionales, con el aditamento que esta educación deberá ser prestada «en la escuela pública».

Para resolver, entonces, la constitucionalidad de la Constitución provincial, la CSJN ofrece la herramienta de la interpretación conforme, considerando que su entendimiento del caso «ofrece una lectura que armoniza de manera razonable la norma provincial con la Constitución Nacional y la ampara por lo tanto de la tacha de inconstitucionalidad alegada por los recurrentes ${ }^{24}$ ».

Su interpretación lleva, en el considerando $16 .^{\circ}$ de la sentencia, a ampliar los efectos de la constitucionalidad al inciso $\mathrm{m}$ del art. 8 de la ley provincial de educación 7546, que simplemente reproduce lo descrito en la Constitución. Claro está, sería incongruente la decisión, si no se llegase al mismo resultado.

\section{LA REGLAMENTACIÓN DE LA ENSEÑANZA RELIGIOSA EN LAS ESCUELAS PÚBLICAS Y LA DOCTRINA DE LA CATEGORÍA SOSPECHOSA}

Salvada la constitucionalidad de los dos primeros pedidos de las accionantes, resta el escollo del inciso ñ del art. 27 de la mentada ley, que reglamenta el derecho establecido en la Constitución de la provincia.

23 Considerando $14 .^{\circ}$ de la sentencia de la CSJN.

24 Considerando $15 .^{\circ}$ de la sentencia de la CSJN. 
La disposición a analizar indica: «Son objetivos de la Educación Primaria en la provincia de Salta: [...] ñ) Brindar enseñanza religiosa, la cual integra los planes de estudio y se imparte dentro de los horarios de clase, atendiendo a la creencia de los padres y tutores quienes deciden sobre la participación de sus hijos o pupilos. Los contenidos y la habilitación docente requerirán el aval de la respectiva autoridad religiosa».

El meollo del asunto redunda en analizar si este artículo vulnera o no los principios de igualdad y no discriminación que derivan del art. 16 de la Constitución Nacional, cuya interpretación refiere a que todos los iguales deben ser tratados de igual manera, siempre que exista igualdad de condiciones.

El examen, por tanto, debe realizarse cuidadosamente, ya que hay que tener presente que la igualdad se da dentro de un grupo de pertenencia $y$, por ello, este estudio debe ser más estricto que cualquier otro posible, ya que quienes se encuentran bajo la posible afección de derechos fundamentales son, ni más ni menos, niños.

Por lo apuntado, la Corte precisa que debe adentrarse al asunto bajo la óptica de la doctrina de las "categorías sospechosas», invirtiendo la carga de la prueba, siendo así el Estado provincial demandado quien debe probar que la diferencia que ha realizado con base en la ley se encuentra justificada al ser el medio menos restrictivo para cumplir el fin que se persigue. Como bien señala la CSJN, «el fundamento de la doctrina de las categorías sospechosas es revertir la situación de desventaja en la que se encuentran los miembros de ciertos grupos para ejercitar con plenitud los derechos reconocidos en el ordenamiento jurídico en razón de muy variadas circunstancias como, por ejemplo, razones sociales, étnicas, culturales, religiosas, entre otras ${ }^{25} \%$.

En el caso, la cuestión sospechosa puede parecer no clara o aparentar ser neutra, ya que la redacción no establece prima facie diferenciación alguna. Ahora bien, en estos supuestos, la Corte es tajante señalando que hay que dar un paso más: hay que analizar la forma en que se implementa la norma para dilucidar claramente si hay o no una inconstitucionalidad de facto.

Claro está, si se comprueba que, en la práctica, existen desigualdades, hay que realizar un segundo paso en el análisis, que implica identificar si la necesidad de diferenciación está suficientemente justificada, ya que, de lo contrario, «la norma aparentemente neutra resultará inconstitucional por afectar el principio de igualdad y no discriminación ${ }^{26}{ }_{\text {". }}$.

En casos en los que la práctica resulta inconstitucional, la declaración debe atacar también al nudo gordiano que la ha causado, esto es, a la norma

25 Considerando $19 .^{\circ}$ de la sentencia de la CSJN.

26 Considerando $22 .^{\circ}$ de la sentencia de la CSJN. 
misma, que es lo que la Corte tratará de realizar al analizar la prueba y verificar que el inciso ñ del art. 27 de la ley de educación provincial es el motor originario de la desigualdad y discriminación. Esta declaración debe hacerse extensiva, además, a la Disposición 45/09 de la Dirección General de Educación Primaria e Inicial provincial, que materializa el contenido legal.

La relación causa-efecto, que deriva de la norma-praxis, es la cuestión central sobre la que diferirá, en su momento, el voto particular, como se verá más adelante.

\section{LA VALORACIÓN DE LA PRUEBA Y EL CONTEXTO SOCIAL}

La Corte valora la prueba aportada a lo largo del expediente y toma en consideración algunos supuestos fácticos, como que la religión católica es profesada por la mayoría de la población salteña, a lo que da en llamar el «contexto social» de la causa.

Es tajante la CSJN al afirmar que «las constancias de la causa demuestran que en numerosas escuelas públicas salteñas se ha adoctrinado a los alumnos en el catolicismo ${ }^{27}$ ». No lo hace sin motivos, ya que toma en consideración las numerosas cuestiones acreditadas al respecto a lo largo del proceso, de las que da cuenta.

Las pruebas de la causa demostraron que no solamente se enseñaba religión católica en el horario habilitado a tal fin, sino que las prácticas excedían el espacio áulico y se desarrollaban en otras instancias de la jornada escolar, lo que afirma la existencia de "patrones sistemáticos de trato desigualitario hacia grupos religiosos minoritarios y hacia los no creyentes ${ }^{28}$ ".

Es esta cuestión material la que suscita el control de constitucionalidad de la ley provincial, la que claramente no se amolda al texto máximo, por cuanto bajo una aparente neutralidad tiene decisivos efectos discriminatorios, violando así los derechos fundamentales al no orientar e inspirar las políticas hacia una educación inclusiva que priorice la plena igualdad de oportunidades.

\section{OTROS (IMPORTANTES) DERECHOS EN JUEGO}

En el marco de la causa, además de los derechos derivados de los principios de igualdad y no discriminación, hay otros tantos que se encuentran en juego. Por ejemplo, el derecho al silencio, que permite que las personas se

27 Considerando $25 .^{\circ}$ de la sentencia de la CSJN.

28 Considerando $26 .^{\circ}$ de la sentencia de la CSJN. 
reserven sentimientos, ideas, acciones y conocimientos que no desean compartir públicamente, lo que se ve afectado por la necesidad de dejar constancia de la opción religiosa que se realiza a través del formulario proveniente de la disposición ministerial. Este «no decir» forma parte de la libertad de conciencia, una de las dos patas junto con la libertad de culto, de la libertad religiosa (Bidart Campos, 2013: 549).

Por otra parte, se afecta el derecho a aprender, el que podría amoldarse a lo dispuesto en la Constitución provincial si se recibieran, como plantea la Corte, contenidos de historia y filosofía de las religiones dentro del plan de estudios y en horario escolar, siempre que su exposición sea objetiva y neutral, cuestión que se desprende directamente de la observación general n. ${ }^{\circ} 13$, numeral 28, del Comité de Derechos Económicos, Sociales y Culturales.

En el sentido de lo expuesto, la Corte expresa una opinión acorde con los tiempos que corren: «Si desde la escuela se promoviera una aproximación histórica y cultural de las religiones, muchos estereotipos se derrumbarían desde la más temprana edad ${ }^{29}$ ». Estas palabras vertidas en la sentencia son aplaudidas por esta tribuna, ya que significan el reconocimiento judicial de una realidad social objetiva.

Lo planteado no es baladí, sobre todo cuando la sociedad avanza en un mundo globalizado e interconectado, donde es necesario abrir la mente frente a nuevos horizontes y propiciar la tolerancia y respeto mutuo. La escuela debería ser un espacio donde se estudien cultura y religión conjuntamente, ya que estas

[....] son dos aspectos esenciales de la persona humana. La historia evidencia una indisoluble unión entre ambas. Las religiones forman parte de la cultura, así como la riqueza cultural de un país está impregnada de lo religioso. Conocer mejor la cultura ayuda a comprender mejor la religión e inversamente. Guardan estrechas conexiones y ambas apelan al núcleo de la identidad personal y social del ser humano, por lo que son elementos importantes en la conciliación de las identidades grupales para alcanzar la cohesión social (Vega Gutiérrez, 2014: 27).

En relación a la libertad de los ciudadanos de expresar su culto es claro que la doctrina de la CSJN apoya su proyección. Ahora bien, en lo que respecta al argumento del acceso a conocimientos de la religión católica que podría afectar a niños desfavorecidos si no se enseña en las escuelas públicas (tal cual lo sostenía el a quo), la Corte exige un juicio de ponderación razonable, por cuanto no se puede favorecer un derecho de manera ilimitada y, por ello, lesionar los derechos de otros grupos que se someten a una situación desventajosa.

29 Considerando $35 .^{\circ}$ de la sentencia de la CSJN. 
La privacidad, que constituye el más íntimo espacio del ser humano, cuya infracción, tal cual lo señala la sentencia, podría «abrir una grieta en el sistema de derechos fundamentales ${ }^{30}$ », también se ve afectada. La religión es algo privado y no son tolerables las políticas de los poderes públicos que exijan romper el halo de intimidad para expresar cuál es, por ejemplo, el sentimiento religioso, si es que se posee.

Para salvaguardar los derechos fundamentales será necesario analizar el costo-beneficio de llevar a cabo una educación religiosa en escuelas públicas, por la afección de derechos fundamentales que ello puede ocasionar. Esta cuestión — considera la Corte— puede salvarse si se cumplen dos requisitos: en primer lugar, que la educación religiosa sea neutral y objetiva, y en segundo lugar, que se realice fuera del horario de clases.

\section{LA DISIDENCIA PARCIAL}

El ministro Horacio Rosatti, constitucionalista, ha sido uno de los dos últimos miembros en incorporarse a la Corte. Como se ha recalcado, esta incorporación ha supuesto nuevos aires de pensamiento, que se reflejan claramente en esta sentencia, a través de un voto que expresa una disidencia parcial.

En su análisis coincide con el voto mayoritario acerca de que se ha acreditado suficientemente que el Estado provincial no ha garantizado la enseñanza simultánea de varias religiones en las escuelas públicas, sino que ha ponderado la enseñanza de la educación católica, tornando a la ley inconstitucional tanto en su ejecución como en su aplicación.

\subsection{La educación religiosa que no vulnera la Constitución}

Del voto llama la atención la dedicación puesta en la argumentación tendente a dilucidar cómo debería desarrollarse la enseñanza religiosa en las escuelas públicas para no ir en contra de lo establecido en la Constitución. Así, considera que esta debe:

a) ser el resultado de un proceso que garantice la participación de la familia y la sociedad en el diseño y control de los programas de estudio; b) asegurar la igualdad de oportunidades y posibilidades de los cursantes, sin discriminación alguna; c) promover -mediante sus contenidos y los métodos pedagógicos utilizados- los valores

30 Considerando $37 .^{\circ}$ de la sentencia de la CSJN. 
democráticos, dentro de los cuales destaca el libre desarrollo de las ideas y la forma de vida (autonomía) y el respeto por la diversidad (pluralismo) ${ }^{31}$.

La participación de la familia en este proceso de diseño curricular va de la mano del derecho que tienen los padres a orientar religiosamente la educación de sus hijos, según sus propias convicciones, lo que concuerda con el contenido derivado de los tratados internacionales, como la Convención de los Derechos del Niño, específicamente su art. 5. ${ }^{\circ}$, como lo afirman Navarro Floria (2018) u Olmos Ortega (2014).

En su análisis, el magistrado realiza un recorrido por el derecho comparado tratando de precisar algunos casos en los cuales la enseñanza religiosa en las escuelas públicas es obligatoria, otros en los cuales es opcional, y otros en los que no verifica su existencia. Este análisis se circunscribe al ámbito europeo y latinoamericano, quizá por la cercanía de los ordenamientos jurídicos.

Del mismo modo, analiza el derecho público provincial para interpretar el margen que poseen las provincias en su diseño constitucional, de conformidad con la autonomía derivada de la Constitución Nacional. Así, identifica algunas provincias que han previsto expresamente la educación religiosa en establecimientos educativos públicos conforme a las creencias de los padres y/o tutores (art. 144, inciso 2 de la Constitución de Tucumán, y art. 270 de la Constitución de Catamarca) y otras en las cuales se prevé la posibilidad de impartir la misma enseñanza, pero fuera del horario de clases (art. 24 de la Constitución de La Pampa y art. 75, inciso 4 de la Constitución de San Luis).

Por otra parte, señala que la Constitución de Córdoba, en su art. 62, inciso 5 , refiere al derecho de los padres a que sus hijos puedan recibir educación religiosa o moral, según sus convicciones, y recuerda que hay otras provincias en las que expresamente se indica que la educación pública es laica o no confesional, como Entre Ríos (art. 258), Mendoza (art. 212), Neuquén (art. 110) o San Juan (art. 80).

En este marco normativo — según el magistrado—, la elección de Salta en nada vulnera la Constitución Nacional, al ser esta decisión adoptada dentro de lo que da en llamar «margen de apreciación provincial» (algo así como una versión criolla del «margen de apreciación nacional»), lo que "permite entender (y convalidar) que ciertas jurisdicciones de nuestro Estado federal pongan énfasis, así como sucede en materia religiosa, en la enseñanza de temas tales como el fomento del espíritu asociativo y cooperativo, el conocimiento

31 Considerando $11 .^{\circ}$ del voto en disidencia parcial del magistrado Horacio Rosatti en la sentencia de la CSJN. 
especial de la historia, cultura y geografía locales, la productividad basada en las características regionales, entre otros ${ }^{32} »$.

\subsection{Libertad religiosa y educación: el diseño curricular como parámetro de constitucionalidad}

La libertad religiosa y el derecho a la educación juegan un binomio difícil de resolver. Al respecto, el magistrado considera que debe existir un reconocimiento armónico de las dos dimensiones de esta libertad (negativa y positiva), lo que implica la posibilidad del ejercicio del derecho a recibir o a no recibir educación religiosa alguna.

Sumado a lo expuesto, entran en juego las cuestiones de minorías y mayorías, que enfrentan al jurista ante una situación difícil de resolver. Considera que no hay que hacer prevalecer mayorías sobre minorías, pues ello se traduciría en una minimización y/o aniquilamiento del derecho de alguno de los sectores en pugna, en lugar de favorecer su máxima expansión posible.

De la confrontación de la cuestión legal con la constitucional, considera que estas materias deben aportar conocimientos generales de creencias y valores, junto con un análisis de los hechos e hitos históricos que sustentan a las distintas religiones existentes. Ello propendería al diálogo y permitiría una construcción actitudinal de ciudadanía desde una temprana edad. Por ello, se exige neutralidad del Estado al diseñar e impartir estas materias.

Lo anterior es el núcleo de su posición particular, lo que se complementa con el pensamiento de que estas asignaturas deben ser diseñadas participativamente, escuchando a padres y tutores, en el marco de un proceso de educación integral. Si se siguiesen estos parámetros — considera el ministro-, la discusión sobre si se dictan dentro o fuera del horario de clases se torna irrelevante.

Este mismo análisis de la conveniencia de la enseñanza de las religiones (que no religiosa) en las escuelas públicas ha sido objeto de estudio, también, por Juan G. Navarro Floria (2018: 2), quien ha dicho al respecto:

Existe un muy amplio consenso en el mundo, que sólo mentes obtusas y enceguecidas por un anacrónico espíritu antirreligioso pueden desconocer, respecto de la necesidad de que en la educación escolar se incluya enseñanza acerca de las religiones. La historia, la política actual, el arte, la música, la literatura, son incomprensibles sin un conocimiento mínimo de las religiones. De su historia, sus principales exponentes, los hechos significativos de su desarrollo, sus símbolos. Todo esto puede ser perfectamente objeto de estudio como lo es la geografía o la botánica. Y como tal,

32 Considerando $18 .^{\circ}$ del voto en disidencia parcial del magistrado Horacio Rosatti en la sentencia de la CSJN. 
como materia de estudio, no demanda la adhesión de nadie, no apela a la fe ni al corazón, sino solamente a la razón.

La discrepancia, también, se centra en que considera que no existe, en la norma, una "categoría sospechosa», tal cual se afirmó en otras instancias y en el voto de la mayoría. Ahora bien, sí que concuerda respecto a que en la práctica han existido vulneraciones de los derechos fundamentales, con clara discriminación entre el alumnado. Su argumento, entonces, se basa en no seguir la línea de razonamiento aportada por la mayoría.

La inconstitucionalidad, entonces, es fáctica, por cuanto se encuentra acreditado con suficiente constancia que ha sido la puesta en práctica de la ley lo que ha significado una afrenta a la Constitución y su contenido. No considera que exista una inconstitucionalidad normativa, pues, según afirma, el reproche de los actos no puede acarrear un reproche a la norma.

\subsection{El fallo en disidencia}

Apartando los puntos II, III, IV y V del considerando $34 .^{\circ}$ del voto del ministro, es posible advertir una serie de cuestiones que llaman la atención. En primer lugar - y como corolario de su pensamiento-, no encuentra inconstitucionalidad en ninguna norma provincial, a diferencia del voto de la mayoría, que sí la declara respecto al inciso ñ del art. 27 de la Ley 7546 y de la Disposición 45/09 de la Dirección General de Educación Primaria y Educación Inicial de Salta.

La consideración de inconstitucionalidad se refiere, por el contrario, a las prácticas que han implicado una prevalencia de un culto sobre los demás y que han discriminado a quienes no profesan cultos o profesan alguno distinto al católico. Considera inconstitucionales, asimismo, la imposición de ritos religiosos y la coerción para expresar la posición personal frente al fenómeno religioso, sea de modo directo o a través de sus padres o tutores. Todo ello ha vulnerado los arts. 14 y 19 de la Constitución Nacional.

Considera, también, que hubo una inconstitucionalidad por violación del principio de igualdad y no discriminación (art. 16 de la Constitución) cuando se obliga a los alumnos a permanecer en el aula cuando se desarrollan clases de religión que no respetan las convicciones de sus padres o tutores.

Al ser estas prácticas inconstitucionales, el magistrado hace dos votos exhortativos al Ministerio de Educación provincial, para que, en el marco de una colaboración sin interferencias, instrumente las medidas necesarias para adaptar los contenidos curriculares de la materia y sus modalidades de implementación, y que disponga el cese de ritos religiosos durante la jornada escolar. También, exhorta a las autoridades locales y provinciales para que 
controlen de manera sistemática el cumplimiento de las pautas fijadas en la sentencia.

Quizá, si este voto hubiera sido el de la mayoría, se hubiera enfrentado a un gran problema: la declaración de inconstitucionalidad es, en Argentina, para el caso en concreto. Frente a esta realidad, el magistrado plantea una expansión de efectos a toda la provincia que, si bien puede ser un canal para evitar futuras inconstitucionalidades, cierto es que rebalsa los límites del caso.

Por lo apuntado, el voto de la mayoría tiene más sustento normativo, ya que debido a la vis expansiva que poseen las sentencias de la Corte, de presentarse otros casos, no deberían los jueces inferiores apartarse de la doctrina sentada. Por ello, al declararse inconstitucional la norma que da origen a las prácticas, inevitablemente se deberían propiciar cambios legislativos que operen una actualización que se amolde a la Constitución.

Al solo declarar inconstitucionales las prácticas, pero no las normas, se puede llegar a un punto en el cual se pretende retorcer la interpretación de la ley hasta hacerla válida con los actos desarrollados por las personas.

\section{CONCLUSIONES}

La sentencia de la Corte Suprema de Justicia de la Nación en el caso Castillo ha puesto sobre la mesa un debate que se viene gestando hace tiempo respecto a la relación entre el Estado y la Iglesia católica. Desde los albores de la independencia, ha sido un tema que ha generado filias y fobias y hoy en día sigue siendo una cuestión que genera diferencias entre distintos sectores de la sociedad.

El bloque de constitucionalidad en su conjunto permite, según la interpretación que se ha realizado, que la enseñanza de la religión se brinde no solo en las escuelas privadas que adoptan un credo determinado, sino también en las públicas. El hecho de que lo permita no implica una obligación de adopción por parte de todos los Estados provinciales ni es un reducto que provenga del sostenimiento debido a la Iglesia; por el contrario, forma parte del amplio margen de apreciación que poseen en su diseño constitucional, lo que va de la mano de una realidad social imperante en cada espacio del amplio territorio argentino.

La sentencia ha reflotado el problema de las inconstitucionalidades que devienen de la aplicación de una norma que vulnera derechos fundamentales por su amplio grado de inconcreción, lo que puede permitir al Gobierno —encargado de aplicar las políticas — hacer que la norma diga lo que aquella no dice $\mathrm{o}$, al menos, no pretende decir. 
Como se ve, lo que se refleja en las palabras del tribunal es un llamado a la sociedad a deliberar y a asumir decisiones adultas y responsables que no vulneren los derechos de los niños ni de los padres o tutores y, por ello, de la familia en su conjunto. La implementación de políticas públicas no puede ser un canal para corromper los derechos de una minoría so pretexto de la existencia en la sociedad de grupos mayoritarios. Argentina respira desde 1983 como sociedad democrática, donde hay que discutir estos importantes asuntos y atender a todas las realidades, no solo la de un sector numeroso de la población.

La decisión de la Corte defiende los derechos de un sector vulnerable de la sociedad: los niños y las niñas. Preserva a este colectivo de las discriminaciones y estigmatizaciones que a una edad temprana pueden representar las convicciones familiares, y llama la atención sobre ello, recordando que se deben construir, en la escuela primaria, valores cívicos y morales que sustenten la tolerancia y el respeto como premisas, tal cual lo presenta Luis Pietro Sanchís (2007).

La escuela debe ser un espacio en el que se puedan transmitir valores que provengan de la Constitución y, por ello, el Estado debe ser neutral en cuanto a la imposición de ideologías en el contenido de las diversas asignaturas que componen el currículo, sea la materia que sea. En este sentido, la posición del maestro Solozábal Echavarría (2007: 141) apoya el argumento.

$\mathrm{Al}$ respecto de lo apuntado, se han hecho actuales las palabras de un deseo expresado por Mariana Catanzaro (2017: 13), tiempo antes de dictarse la sentencia, cuando sostuvo:

Será esta la oportunidad para que la Corte Suprema de Justicia de la Nación instruya recordando cuáles son los propósitos para la escuela pública. Debiera darse una sentencia ejemplar, desechando cualquier distinción y en cambio fomentar la inclusión y el respeto por las individualidades y los derechos humanos. De modo contrario, el riesgo será que las minorías no gocen de los mismos beneficios de la mayoría, sino que sufran la tiranía de la mayoría.

Por fin, esta tribuna aplaude la decisión de la Corte, que trata de lograr una salida coherente para la educación religiosa en las escuelas públicas, cual es la de que esta materia, siempre bajo la premisa de la neutralidad y asumiendo las distintas realidades de los creyentes, sea dictada fuera del horario escolar, realizando así un esfuerzo cuyo coste es increíblemente inferior que el quebranto de los derechos.

\section{Bibliografía}

Bazán, V. (2006). El amicus curiae en el Derecho Comparado y su instrumentación reglamentaria por la Corte Suprema de Justicia Argentina. Anuario Iberoamericano de Justicia Constitucional, 10, 15-50. 
Bidart Campos, G. J. (2013). Manual de la Constitución Reformada (tomo I). Buenos Aires: Ediar.

Botana, D. (2018). Religión y neutralidad en los orígenes de nuestra Constitución Comentarios a propósito del fallo Castillo. La Ley Online, AR/DOC/162/2018.

Calderone, S. (2017). La educación religiosa en las escuelas públicas ante la Corte: comentarios al dictamen de la Procuración General de la Nación. La Ley Online, AR/DOC/2475/2017.

Calvo Espiga, A. (2017). Religión y poder político: una perspectiva histórica. En M. Á. Asensio Sánchez et al. Fenómeno religioso y ordenamiento jurídico (pp. 13-47). Tecnos: Madrid.

Carranza, G. G. (2017). Una nueva óptica sobre el control de convencionalidad en Argentina. Comentarios a la resolución de la Corte Suprema de la nación en el asunto Ministerio de Relaciones Exteriores y Culto. Anuario Iberoamericano de Justicia Constitucional, 21, 161-185.

Catanzaro, M. (2017). El caso de la educación religiosa en las escuelas públicas de Salta. Reflexiones tras las audiencias ante la Corte Suprema de Justicia de la Nación. Microjuris, MJ-DOC.12297-AR / MJD12297.

Gelli, M. A. (2011). Constitución de la Nación Argentina comentada y concordada. La Ley: Buenos Aires.

Gil Domínguez, A. (2017). Neutralidad estatal, y libertad religiosa y de conciencia. La Ley Online, AR/DOC/2233/2017.

Mena Vázquez, J. (2010). El amicus curiae como herramienta de la democracia deliberativa. Revista Justicia Electoral, 1 (6), 173-196.

Navarro Floria, J. G. (2018). El derecho de los padres a educar a sus hijos. Reflexiones a partir del caso Salta. La Ley Online, AR/DOC/2979/2017.

Olmos Ortega, M. E. (2014). El derecho de los padres a decidir la formación religiosa y moral de sus hijos. En I. Cano Ruiz (ed.). La enseñanza de la religión en la escuela pública (pp. 19-41). Comares: Granada.

Pietro Sanchís, L. (2007). La escuela (como espacio) de tolerancia: multiculturalismo y neutralidad. En A. López Castillo (ed.). Educación en valores. Ideología y religión en la escuela pública (pp. 51-70). Madrid: CEPC.

Pinaccio, Á. C. (2017). El amparo colectivo. Microjuris, MJ-DOC-10744-AR / MJD10744.

Solozabal Echavarria, J. J. (2007). La enseñanza de valores entre la libertad ideológica y el derecho a la educación. En A. López Castillo (ed.). Educación en valores. Ideología y religión en la escuela pública (pp. 137-146). Madrid: CEPC.

Vega Gutiérrez, A. M. (2014). Diversidad, religión y cultura en la educación. En A. M. Vega Gutiérrez (coord.). La gestión de la diversidad religiosa en el sistema educativo español (pp. 27-71). Thomson Reuters Aranzadi: Madrid. 